\title{
Development of the Smart Grid: Missing Elements in the Policy Process
}

\author{
Richard D. Tabors \\ CRA International \\ rtabors@,crai.com
}

\author{
Geoffrey Parker \\ Tulane University \\ gparker@tulane.edu
}

\author{
Michael C. Caramanis \\ Boston University \\ mcaraman@bu.edu
}

\begin{abstract}
This paper seeks to frame one aspect of the Smart Grid discussion which has been under-recognized in regulatory and policy debates. Significant discussion has focused Smart Grid attention on the technologies and on technical interoperability, there has been, we argue, too little attention to questions of the structure or the operation of the market(s) in which the technologies will function. The authors contend that the market structure required for a successful Smart Grid is best understood considering a "platform" framework. We present our view of the interrelationship between that market platform, ultimate customers and power suppliers. It is our conclusion that without a thorough vetting of the market structure within which Smart Grid technologies will function, the full value of the innovations can not be realized.
\end{abstract}

\section{Introduction}

Developments in the capabilities for sensor and digital control technologies (as opposed to the current analog controls) and improved communication of digital data and information have opened a large range of new options for both the wholesale (transmission) and retail (distribution and behind the meter) segments of the industry.

While in the past, analog devices and expensive communications required that power systems control be highly centralized, these new capabilities and their economics now create the potential for a paradigm shift in the electric power industry. That shift allows for distributed decision and control through direct customer choice and involvement in the power system "equation" (e.g., through demand response mechanisms and/or distributed energy resources such as rooftop solar installations.) These technological changes will allow for the evolution of a genuine integrated market in electricity - one in which the demand and supply sides interact in a fully functional market.

\section{A Vision for the Smart Grid: The Market Platform}

The US Federal Energy Regulatory Commission (FERC) presented a Proposed Policy Statement and Action Plan (issued March 19, 2009) [6]. That statement offered significant argument for technical standards for interoperability but provided little guidance on the platform of platforms that are being considered or upon the level and quality of information that will flow for operations and control of Smart Grid devices. The authors, argued and their point was acknowledged in the resulting FERC report, that to overlook the market was to overlook the mechanisms of implementation of smart grid. [

Utilities understand their business of delivery of electricity to end-use consumers and are justifiably proud of the achievements they have made in the near-universal delivery of reliable power. What they have had little incentive to develop, however, is a detailed characterization of their retail customers in the particular as opposed to their customers in the aggregate. While economic dispatch (and the underlying economic theory of it) reflects the realities of the moment-to-moment costs of generation and delivery, the concept that these costs can and should be directly related to the prices seen by customers is totally missing in the current environment. The status of the current electric system is reminiscent of the old "Ma Bell" telecommunications system where innovation occurred safely behind the walls of the local telephone exchange. In many ways it appears that we are seeing a "Pa El" to go with Ma Bell with $\mathrm{Pa}$ El attempting to maintain full control of a system claimed to be too complex for consumer participation. 
In her recent book "Deregulation, Innovation and Market Liberalization: Institutional Change in the Energy Sector," Lynne Kiesling captured the essence of the current utility structure when she stated that the structure of supply without demand response was the equivalent of "one hand clapping."[9] Kiesling accurately and effectively presents the current condition of the industry and its regulatory structure as being based on a static view of the world: utilities supply all consumer demand at a flat rate that is independent of both individual customer preferences and the cost of energy at a specific location in anything close to real time. By this design, the electric utility logic for decision and control is unidirectional.

Dr. Kiesling has correctly pointed out that "this failure to acknowledge agent heterogeneity [individual customer differences] in the rate structure accounts for the extreme price inelasticity of demand that has historically held in the industry." She challenges, and we agree, that with technological development the paradigm can and must change to one that is dynamic, marked by decentralized coordination and adaptive institutions, and achieves a better match of marginal costs to marginal demand.

Advanced technologies under the umbrella of Smart Grid provide the opportunity to alter the one-sided decision and control structure by moving distributing - the decision and control to individual consumers. The key concept is that the decision to consume is a distributed decision based upon the welfare of the individual consumer. The aggregate of these individual decisions determines the quantity, cost and quality of electricity provided (by location and time) to the consumer.

However, the individual elements of the Smart Grid do not stand on their own. Utilities, developers, and vendors assume that these individual elements will function as part of an interactive, integrated system, and the elements will come together in different ways over time and at different locations within the electric grid. The implication of this currently disparate environment is that a key missing element of the vision is the signal; that is to say, the information that can be used on "platforms" to allow the logic of the applications to make "smart" decisions on when to run, charge, or discharge, which will result in individual benefit from commensurate system cost reductions.

The concept of a platform or set of platforms in the Smart Grid market suggests the adaptation to energy of the evolution that took place within the communications industries, where a set of tools that match service providers to customers with complex markets is defined as a platform. This model has proven useful in describing markets for products such as personal computers, computation services, cell phones, gaming systems, streaming media, and telecommunications infrastructure. In these markets developers build applications on top of a platform. As we have seen in multiple industries, such systems have become an important way in which firms organize innovation. However, for platform innovation systems to function, the market rules (and regulations) governing access and intellectual property must be carefully analyzed, designed, monitored and enforced.

The authors propose that the "platform" is a useful framework with which to understand how Smart Grids can and will evolve. Further, it is a convenient analytic paradigm to use in order to avoid the pitfalls that might otherwise stall the development of an important and socially beneficial industry. [5] [11]

The authors have a common concern that the current technology driven focus and enthusiasm for new Smart Grid systems could lead to the premature adoption of standards that might enable a few important applications, but would be inflexible to unexpected innovations that hold the potential for increased profit and social benefit. Realizing the full potential of Smart Grid benefits is particularly important given the unique qualification of the Electric Power Industry to conserve fossil fuels heat pumps are much more efficient than burning fuel for heat - and to substitute $\mathrm{CO}_{2}$ emitting oil in the transportation sector with clean power generation.

Will the Smart Grid be instrumental in mitigating the cost of investment in the physical Power System infrastructure that is required to handle clean generation intermittency and increased transportation sector loads? There is a need for an appropriate balance of investments in the CyberPhysical components of the Smart Grid platform and an appropriate utilization of these investments that can help to facilitate an affordable and sustainable energy future. The key issue is how to achieve this potential. We argue that this potential can be achieved in a market environment that accommodates multiple competing developers and multiple competing users and service-providers.

Experience in other industries that have gone through the transformation facing the electricity industry today indicates that few firms are able to provide a full complement of service applications for their platforms. Once the initial applications of 
efficiency, price response, and distributed generation are accommodated, what else might we expect to see on the Smart Grid platform? If the history of platforms like Apple's iPhone is any guide, then we might be surprised. At first, the iPhone provided telephony and multimedia functionality supplied only by Apple. However, once the platform was opened to developers, a thriving developer-led ecosystem grew quickly to deliver thousands of applications in diverse categories of business productivity, news, and games. Firms have learned that it is economically beneficial to rely on developer pools to extend their platforms' functionality. However, for the developers to participate there must be access, not only in an engineering sense, but also in an open contractual sense.

As Figure 1 shows, the opening of core platforms provides for significant social benefits beyond those of the single developer able to initiate only a limited number of valuable applications.

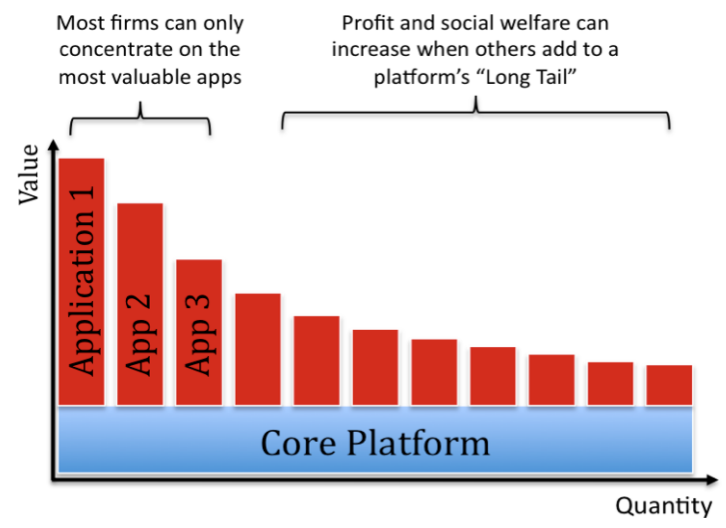

Figure 1: Platform value can increase when 3rd party developers add applications. [4]

Having the flexibility to mix and match the elements of the Smart Grid works best when the individual technical elements and their markets can operate on a known platform or platforms with a set of rules and regulations that reflect "good" economics. These are the signals that hold the system together both logically - the economics - and structurally - the regulation. Innovation is market driven; applications are market driven; consumer response is market driven. Market demands have driven the applications that we find on the open platforms of the Internet. Expectations of the future availability of interoperable platforms and their concomitant markets are driving the Smart Grid applications available today. What appears to be missing is an agreement or even a discussion of the regulated market signals that will provide the information for socially efficient consumption, valuation of renewables when and where delivered, values for carbon emissions when and where emitted, and the trigger for charging and discharging of distributed storage in applications such as Plug-in Hybrid Electric Vehicles (PHEV).

PHEVs may, however, be a critical point of introduction for incorporation of market signals on a common platform. As reported in SmartGridNews on September 8, 2009, GridPoint with their "Smart Charging" technology has teamed with a range of transport technology companies as well as Nissan Motors to put 5000 vehicles and up to 12,750 charging stations in 5 states. [15] The complexity of PHEV charging and discharging and the potential for its use as distributed storage will require some form of market pricing information for scheduling and a common platform for operations.

As stated in the introduction, the electric utility always has operated in real time based on short run economic signals. System Lambda used in dispatch is the calculation of the marginal cost of the marginal unit being brought on line to serve load. The work of Schweppe, Caramanis, Tabors and Bohn in Spot Pricing of Electricity is now over two decades old. [14] While still the basic text in the mathematics of locational marginal pricing and transmission pricing and analysis, the basic message of that work has still to be implement - the translation of the realtime cost of generation and delivery of electrical energy to the price paid in real-time by the consumer.

Smart Grid (along with Federal legislation and regulation) may bring the concepts of Spot Pricing to customers, but only when and if the development of a full market picture of the benefits of Smart Grid is developed that incorporates a functional platform paradigm and the signals - most likely to include real-time prices - is instituted.

\section{THREE PILLARS OF THE SMART GRID}

To understand Smart Grid in its consumer context, it is necessary to break the problem into the three interrelated elements that directly affect the consumer end of the system. [17]

- The first of these is what we would call the "Smart Customer." That is the set of technologies that exists or are under development by which electricity consumers 
will be able to observe, directly control, or allow silicon to control their electricity consumption.

- The second is the "Smart Utility." That is the utility that is implementing sophisticated monitoring, digital controls and locational pricing, as well as reaching out to its customers with programs and plans for "smarter" consumption.

- The third element is the "Smart Market." That is the structure of the market that allows for the integration of the technologies, decision logics and information at the customer and the utility end to create an economically efficient solution in the new dynamic paradigm that the digital technology has created.

Figure 2 presents graphically the elements of the Smart Grid at the customer end of the wires and includes the relationships between both the three elements and the other physical and economic players in the market.

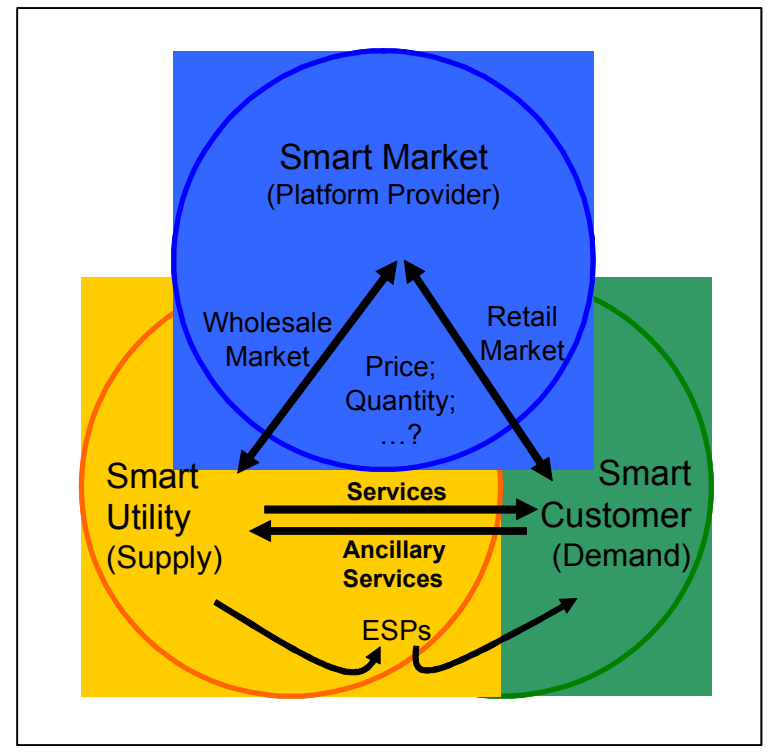

Figure 2: Defining the overlap of these elements will determine the character of the Smart Grid.

The Smart Customers are being bombarded with technology to assist them in operating their homes and commercial facilities more cost effectively. That there is a need for these technologies to be interoperable is without argument. Whether wired or wireless, the ability for information to be exchanged between devices is critical to their (individual or collective) ability to make rational decisions on energy consumption or supply of energy to the grid. But in order to be "smart," the customer will rely on a choice of products - or applications to simplify and communicate their choices for consumption. Such products, whether offered by a utility or a third-party Energy Service Provider (ESP), require the market to exist and the platform to be defined.

The Smart Utility is also being overwhelmed with new technology but at two levels. At the transmission level there is increased pressure for advanced monitoring and new sensing and control devices, from phasor monitoring units to variable frequency transformers. At the customer level there is increased pressure for AMI and AMR (Automatic Metering Infrastructure and Automatic Meter Reading) devices that can receive price information, report consumption, and respond to control signals.

At all levels, however, there are unresolved questions of exactly what this information will be. In what form will it be exchanged, how frequently and, critically, who "owns" it? Collectively, the outcome to those questions will form the platform on which the Smart Grid develops.

\section{Missing Elements}

AMR AMI: There is a set of elements to the smart grid that represent, in some sense, a sine qua non in that the elements are needed between the current utility and the consumer. As stated above, the current vocabulary for these elements is AMR and AMI technology. The issue is that the automation element referenced is focused on the data gathering (and in the case of two way communication based systems) the data sending. In the world of Smart Grid the more key element, we have argued, is the data sending both in terms of quality (information and decision making value) and quantity.

While much has been written about the need for specifically some form of AMR in Smart Grid, only limited effort has been applied to understanding the cost consequences. Hydro One in Ontario has completed installation of 1 million Smart Meters with a goal of having all customers see time-of-use pricing by 2010. [16] Southern California Edison (EIX) reported in September of 2008 that they would be installing 5.3 million consumer smart meters at a total cost of 1.6 billion between 2009 and 2012. They applied to the CPUC for recovery of the costs.[2] This reflects a cost of approximately $\$ 300$ per meter. At roughly the same time Baltimore Gas \& Electric 
proposed expenditure of $\$ 500$ million to replace all residential and business meters. The program would cost roughly $\$ 200$ per meter [8].

BGE in their request to the Maryland Public Utility Commission stated that the cost could be reduced to \$200 Million with a Federal Stimulus grant. More interesting is that they stated that their expectation was to achieve a $\$ 2$ Billion benefit from consumer response, with principle amount coming from response at peak implying (but not stating) that this would be in response to price.

In both the examples, SCE and BGE, the questions before the commissions are what the cost of the metering systems - implied to be for Smart Grid - will cost and what will be the anticipated rates of acceptance of these technologies? SCE has requested an additional $\$ 1$ per month per customer to cover costs and BGE has requested an initial amount of $\$ .38$ rising to $\$ 1.24$ over the 5 years of the program.

Steve Piper, using plausible assumptions concerning the size of the average SCE customer load and the current SCE tariff structure estimated that the payback for the $\$ 300$ smart meter would be 2.8 years against a TOU structure. [12] When a significant penetration of smart appliances are added the estimate is that the payback shortens to roughly 2 years. His point of comparison is, however, that Compact Florescent Lights have a payback of only .6 years indicating that replacing incandescent bulbs is yet more cost effective.

Price Response: A critical element of the Smart Grid for consumers is the underlying assumption that consumers will respond to the information received and modify their pattern (if not total amount) of consumption. The debate remains; will there be a response?

The work of the current authors on RealTime Pricing (RTP) or Spot Pricing of electricity is premised on the assumption of economically rational consumer response. The US Congress in the Energy Independence and Security Act of 2007 [4] (EISA) has mandated that utilities translate their real-time costs to customer prices. The EISA goes on to require the unbundling of rate structures to allow utilities full recovery of cost; and most significantly, the coordination of wholesale and retail markets.

Consumers of electricity, particularly residential consumers, are, however, generally (and correctly) perceived as being highly price inelastic. The literature abounds with discussion of inelasticity in relatively flat rates and in limited analyses of real time rates [10]. While there is limited evidence of significant response to price by smaller customer with minor increases price, there exists a single social experiment on that incorporated dramatic increases in price for a short period of time and that was the 2000 / 2001 "meltdown" of the California electricity market.

Reiss and White in their study of consumer behavior during the California Energy Crisis published in 2008 provide an analysis of the response to a dramatic price change that occurred in June of 2000 and remained in effect through September of 2000 in which (month on month 1999 to 2000) San Diego customers reduced demand by $13 \%$ in response to a doubling in prices. [13] However, when prices were capped and returned roughly to pre price spike levels, customer demand returned to prior levels as well. The reported statistics show the nearly immediate dramatic drop in demand - and the equally dramatic recovery when price caps were ordered.

Despite the pressure of the government for additional information reaching consumers, only $6 \%$ of general Consumers and, surprisingly $4 \%$ of "Green Elite" consumers favor providing real-time information about energy use to assist utilities to more efficiently meet energy demand based on the Burson-Marsteller (BM) 2009 Green Power Progress Survey [1]. This same survey reports that nearly two thirds of both categories support additional government investment in smart grid technology and over $50 \%$ believe that consumers have access to data about their energy consumption habits which they can use to lower their energy bills. In general consumers believe that smart grid is the answer to a wide range of issues.

Among the most interesting outcomes of the BM survey were the findings indicating how much consumers were willing to pay on average for smart grid services. As a once only payment the value was $\$ 48$ for the average consumer and $\$ 70$ for the Green Elite. The value for the monthly average reported was $\$ 13$ for average and $\$ 35$ for Green Elite. Granting that Smart Grid is far more that AMR/ AMI, it is interesting to note that the monthly value reported is well in excess of what is being considered for the metering costs by either SCE or BGE.

The conclusion of the survey is that consumers are very unclear about what smart grid may be capable of bringing. 


\section{Where do we go from here?}

There are currently a multitude of opportunities for all of the Smart Grid technology developers to argue for standards and conditions of interoperability. From a policy perspective the missing link is a definition of the information that will flow on the platform or platforms of the Smart Grid. The challenge will be for the FERC at the federal level to acknowledge its role in the economic regulation of the US (and in many ways North American) grid system. Critical to this federal activity will be the coordination with state PUC activities, in effect, to make peace with the State Regulatory authorities (or at minimum arrive at a sharing relationship). Assuming peace is possible, this will allow for the development of the broadly based conditions that will provide the incentives for platform development and will provide for the definition of the "signals" - we argue price signals being the most critical - that will be used by end consumers in taking advantage of the technology developments.

Definitions of the boundary between the Federal and State authority will not be simple. Many states have already taken significant steps in both the encouragement of Smart Grid technology and in restructuring of retail rates - unbundling of the relationship between $\mathrm{kWh}$ and revenue. Probably the most critical issue will be to identify the respective Federal and State regulatory barriers to implementation of all elements of the Smart Grid. In that effort, the existing FERC-NARUC Smart Grid Collaborative could be a valuable framework for initiating that discussion. The Smart Grid Collaborative, however, is illustrative of the general predisposition in Smart Grid policy activity toward technical development at the expense of market enablement. While the Collaborative was established with a general mission of "facilitating the transition to a smart electric grid," [7] like so much other activity in recent years it has become more narrowly focused on advancing the conditions for interoperability of the Smart Grid.

From the perspective of the development of the Smart Market, one central element vehicle for progress as mentioned above, is Section 1307 of the EISA that includes a Real-Time pricing requirement, amended to the Public Utilities Regulatory Policy Act of 1978 (PURPA). More specifically, Section 1307 states that:

Purchasers and other interested persons shall be provided with information on-(I) time-based electricity prices in the wholesale electricity market; and (II) timebased electricity retail prices or rates that are available to the purchasers.

Furthermore, the law requires that such data be provided on a not less than daily interval, and should include hourly price and use information as well as a day-ahead price projection. Each state regulatory authority was required to commence consideration of these mandates one year following passage of the 2007 law, and shall complete such consideration by the end of 2009.

This real-time pricing requirement is, we argue, a key enabler of the Smart Grid market platform, and one in which FERC along with the State Regulatory authorities will need to take a lead. Results on real-time pricing consideration are due from each state by the end of 2009. While little evidence of compliance with this legislation is in evidence, it is likely that most states will comply even if only in form by the deadline. These results could provide a first look at the Smart Market as opposed to the smart technologies of the Smart Grid.

\section{Conclusions}

Dramatic change is coming to the electric power generation, transmission, and distribution industry. The recent Federal stimulus plan includes several billion dollars to facilitate the development and deployment of a "smart grid." Although there have been major improvements in transmission and distribution technologies, the basic elements of the electric power system have remained unchanged since the days of Thomas Edison. That is all about to change as utilities prepare to accommodate new "applications" that promise improved real-time price response systems, more efficient delivery mechanisms, the integration of intermittent resources into distributed generation, increased options for energy-use management, and improved robustness to natural events such as hurricanes and ice storms.

It is now clear that all of the elements of the Smart Grid, including the Smart Market, are going to be designed and vetted under the careful eye of the National Institute of Standards, the Department of Energy and the Federal Energy Regulatory Commission, the State Public Utility Commissions and Consumer Advocates. No entity has clear responsibility for all of the moving parts and the opportunity for turf wars abounds. 
The role of the market and market forces appears to be strong and with current government stimulus funding from both States and the Federal government. There is tremendous activity in the area of metering, sensors, and control systems as firms develop new smarter products to supply the market. However, before new systems are widely deployed, the rules of engagement will have to be carefully crafted. The forces of the market will need to be strong enough to work through and around the administrative challenges to find solutions beneficial to consumers and to the suppliers.

\section{References}

[1] Burston-Marsteller 2009 Green Power Progress Survey' "A Study of Consumer Demand for Green Power Infrastructure, Renewable Energy \& Technologies" http://www.slideshare.net/bursonmarstellerUS/2009-greenpower-progress-survey-1825331

[2] Lee Bruno, Cleantech Group, http://cleantech.com/news/3484/utility-commissionapproves-16b-smart-metering-program

[3] Michael C. Caramanis, Geoffrey Parker and Richard D. Tabors, "Comments" submitted to the Federal Energy Regulatory Commission on the Smart Grid Policy Statement, Docket No. PL09-4-00, May 11, 2009.

[4] Energy Independence and Security Act of 2007, Pub. L. No. 110-140,121 Stat. 1492 (2007) (EISA).

[5] Thomas R. Eisenmann, Geoffrey Parker and Marshall Van Alstyne "Opening Platforms: How When and Why?" Harvard Business School Working Paper 09-030, August 2008.

[6] Smart Grid Policy, 126 FERC \ 61,253 (2009).

[7] Federal Energy Regulatory Commission. "Federal, State Regulators Convene Collaborative Dialogue on 'Smart Grid'." News Release: February 14, 2008. (http://www.ferc.gov/news/news-releases/2008/2008-1/0214-08.asp)

[8] Liz F. Kay, “"BGE Announces Plan for Smart Meters," The Baltimore Sun, July 14, 2009.

[9] Kiesling, Lynne. Deregulation, Innovation and Market Liberalization: Institutional Change in the Energy Sector. Routledge: New York, 2009. (111).

[10] Marc Lijesen, "Real time price elasticity of electricity," Energy Economics, Volume 29, Issues 2 March 2007, pp. 249-258.

[11] Geoffrey G. Parker and Marshall W. Van Alstyne, "Two-Sided Network effects: A Theory of Information
Product Design" Management Science, Vol. 51, No. 10, October 2005, pp. 1494-1504.

[12] Steve Piper "The Smart Meter Vanguard of the Smart Grid" reporting in The Oil Drum, Drumbeat July 24.2009 www.theoildrum.com

[13] Peter C. Reiss, Matthew W. White. "What changes energy consumption? Prices and public pressures", The RAND Journal of Economics, Volume 39, Issue 3, Date: Autumn 2008, Pages: 636-663

[14] Fred C. Schweppe, Michael C. Caramanis, Richard D. Tabors and Roger E. Bohn Spot Pricing of Electricity Kluwer Academic Press, Boston, 1989

[15] "SmartGrid Software Leader GridPoint to Provide Smart Charging Software for Largest US Electric Vehicle Rollout" SmargGridNews September 8, 2009.

[16] "Smart Installations: grids, meters \& solar panels," IEEE Power \& Energy Vol. 7; Number 5, September/Octover 2009, p.82.

[17] Richard D. Tabors, "The Smart Grid's ultimate (and sustaining) enabler" SmartGridNews July 2009, http://www.smartgridnews.com/artman/publish/Business Markets Pricing News/Three Pillars of the Smart Grid$\underline{636 . h t m l}$ 